\title{
Current landscape and future directions of biomarkers for predicting responses to immune checkpoint inhibitors
}

This article was published in the following Dove Press journal:

Cancer Management and Research

\author{
Yingming Zhu' ${ }^{1,2}$ \\ Fen Zhao' \\ Zhenxiang $\mathrm{Li}^{\prime}$ \\ Jinming $\mathrm{Yu}^{\prime}$
}

'Department of Radiation Oncology, Shandong Cancer Hospital and Institute, Shandong University, Jinan, China; ${ }^{2}$ Department of Radiation Oncology, China-Japan Friendship Hospital, Beijing, China
Correspondence: Jinming Yu Department of Radiation Oncology, Shandong Cancer Hospital and Institute, Shandong University, 440 Jiyan Road, Jinan 250 II7, Shandong, China

Tel +8653 I 87984729

Fax +86 5318798 4079;

Email yujinmingsd@।26.com

\begin{abstract}
Immune checkpoint inhibitors (ICIs), represented by anti-CTLA-4 or anti-PD-1/ anti-PD-L1 pathway antibodies, have led to a revolution in cancer treatment modalities. ICIs have unique clinical benefits, such as effectiveness against a broad range of tumor types, strong overall impact on survival, and persistent responses after the cessation of therapy. However, only a subset of patients responds to these therapies, and a small proportion of patients even experience rapid progression or an increased risk of death. Therefore, it is imperative to optimize patient selection for treatment. This review focuses on the mechanisms of tumor escape from immune surveillance, the composition and activity of a preexisting immune infiltrate, the degree of tumor foreignness (as reflected by the mutational burden, expression of viral genes, and driver gene mutations), and host factors (including peripheral blood biomarkers, genetic polymorphisms, and gut microbiome) to summarize current evidence on the biomarkers of responses to ICIs and explore the future prospects in this field.
\end{abstract}

Keywords: immune checkpoint inhibitor, programmed death-1, programmed death ligand-1, cytotoxic T-lymphocyte-associated antigen-4, biomarker, efficacy

\section{Plain language summary}

The significant differences in patients' responses to immune checkpoint inhibitors (ICIs) have generated intense interest in identifying biomarkers to guide patient selection.

We summarize current potential biomarkers for the prediction of ICI efficacy, focusing on four levels (the mechanisms of tumor immune escape, the composition and activity of the immune system in the tumor, the foreignness of the tumor, and host factors).

Multivariate analyses must consider a variety of variables, including the aforementioned four aspects to identify the combinations of factors that predict patients' response to ICIs.

\section{Background}

Cancer immunotherapy has undergone revolutionary progress in recent years, mainly due to the breakthrough regarding the extraordinary clinical outcomes associated with immune checkpoint inhibitors (ICIs) targeting the cytotoxic T-lymphocyte-associated antigen (CTLA-4) and programmed death-1 (PD-1)/programmed death ligand-1 (PD-L1) pathway. Although the heterogeneity of somatic mutations in tumors raises challenges for the methods that target a single mutation, it also raises the possibility of using the large number of neoantigens to induce immune responses to kill tumor cells. However, the recognition and cytotoxicity functions of the innate and adaptive 
immune systems are inhibited by immune checkpoint pathways. Based on this theory, many ICIs, such as CTLA-4 and PD-1/PD-L1 pathway inhibitors, have emerged. CTLA-4 inhibitors mainly affect the early stage of the immune responses, during T-cell priming and activation, blocking the contact inhibition functions of regulatory $\mathrm{T}$ cells (Treg) on effector T cells (Teff) and thus enhancing Teff functions. ${ }^{1,2}$ PD-1/PD-L1 inhibitors mainly exert their effects primarily on immune responses within the tumor microenvironment (TME); they can reverse the status of Teff cell anergy and depletion to restore tumor cell killing functions and induce effective anti-tumor immune responses. ${ }^{3,4}$

\section{Materials and methods}

To summarize the recent research on the biomarkers of ICIs, we searched the PubMed database, using the following search terms " $(((($ (checkpoint) OR PD-1) OR PD-L1) OR CTLA-4) AND ((inhibitor) OR blockade)) OR (((anti-PD-1)
OR anti-PD-L1) OR anti-CTLA-4) AND (((biomarker) OR predictive) OR prediction) AND response". PubMed was last searched in May 2018. A flow diagram of this review is presented in Figure 1. Eligible trials in https://www.clinicaltrials.gov were also included in the survey. Additionally, reports from annual meetings of the American Society of Clinical Oncology and the European Society for Medical Oncology were searched through these organizations' official websites at http://meetinglibrary.asco.org/ and http://www. europeancancercongress.org.

\section{Biomarkers to predict responses to ICls}

The advance of ICIs has revolutionized the approach of cancer treatment. The unique advantages of ICI therapy, such as crossing different histological types of tumors, significant elongation of the survival period, and persistent effectiveness after drug withdrawal, have generated widespread

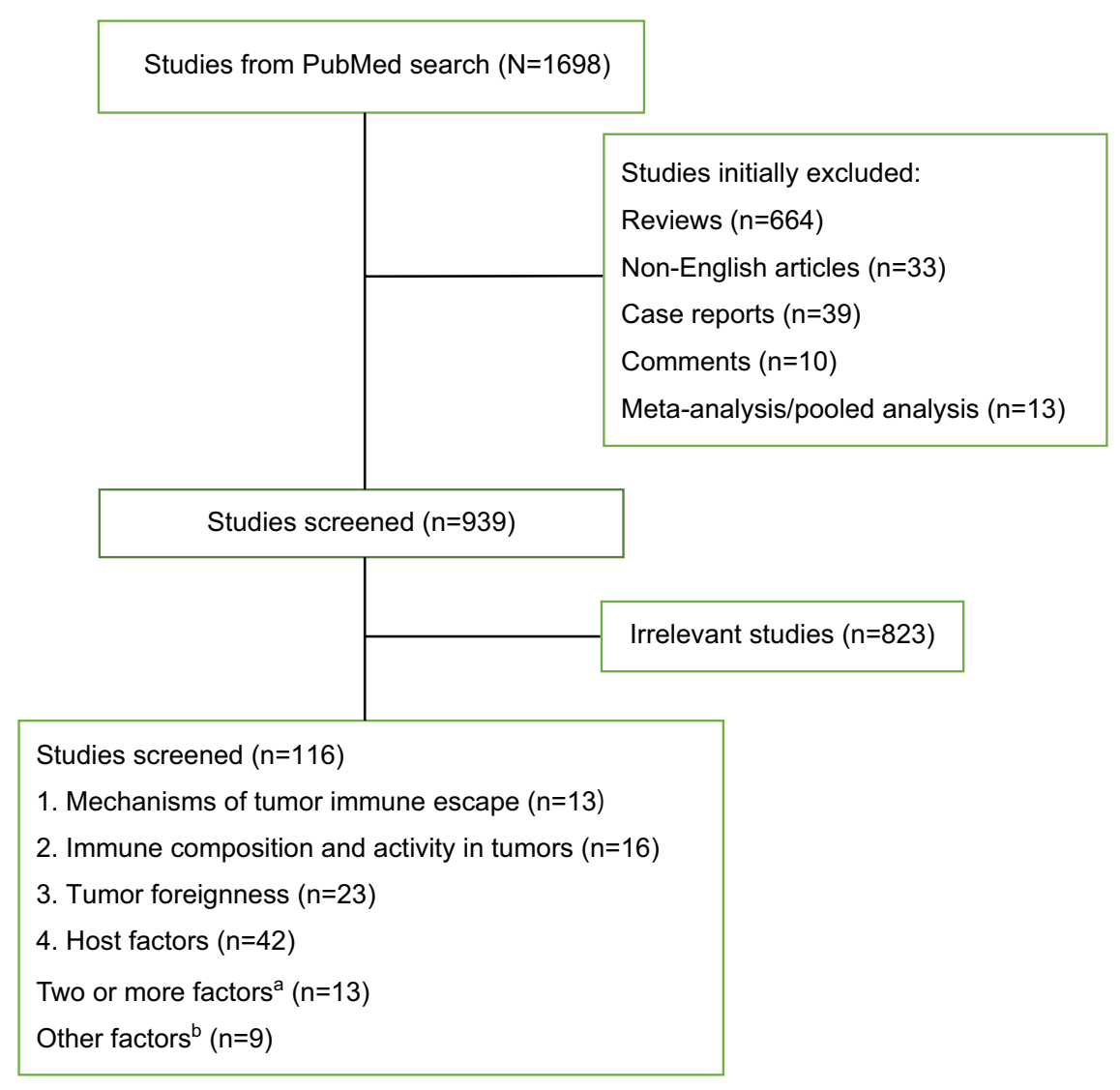

Figure I A flow diagram of this review.

Notes: aStudies of two or more factors included: mechanisms of tumor immune escape and tumor foreignness $(n=5)$; mechanisms of tumor immune escape and immune composition and activity in tumors ( $n=4)$; mechanisms of tumor immune escape, immune composition, and activity in tumors and tumor foreignness ( $n=2$ ); tumor foreignness and host factors $(n=I)$; immune composition and activity in tumors, tumor foreignness, and host factors $(n=I)$. ${ }^{\circ}$ Other factors included: studies about PET-CT, CT, and MRI parameters $(n=4)$, and studies about clinical factors such as age, KPS, and so on $(n=5)$.

Abbreviations: KPS, Karnofsky Performance Status; PET-CT, positron emission tomography-computed tomography. 
enthusiasm among patients, clinicians, and scientists. However, the heterogeneity of responses to ICIs has also generated new challenges. To date, anti-CTLA-4 therapy has shown reproducible activity only in patients with malignant melanoma (MM). ${ }^{5,6}$ In contrast, PD-1/PD-L1 inhibitors have a broad range of activity extending beyond $\mathrm{MM}^{7-9}$ to an expanding list of cancers, including non-small-cell lung cancer (NSCLC), ${ }^{10-12}$ renal cell cancer (RCC), ${ }^{13}$ head and neck squamous cancer (HNSCC), ${ }^{14,15}$ bladder cancer, ${ }^{16,17}$ and Hodgkin's lymphoma. ${ }^{18}$ However, certain types of cancer, such as prostate cancer and pancreatic cancer, have proven to be much more resistant to PD-1/PD-L1 inhibitors. ${ }^{19}$ Champiat et $\mathrm{al}^{20}$ even reported that a small group of patients $(\sim 10 \%)$ showed rapid progression after treatment with anti-PD-1/ PD-L1 drugs. The US Food and Drug Administration (FDA) recently issued a statement requiring the cessation of trials of pembrolizumab in combination with dexamethasone and an immunomodulatory agent (lenalidomide or pomalidomide) for the treatment of patients with multiple myeloma due to the increased risk of death to patients in two recently halted clinical trials. ${ }^{21}$ The above-mentioned facts underscore the need for biomarker development. Given the dynamic nature of the immune system and the complexity of immune responses, the identification of the biomarkers of ICIs is more challenging than the identification of the biomarkers of targeted therapy. Based on research performed to date, four prerequisites, namely, tumor antigen release, tumor antigen presentation, attenuated immune suppression, and tumor antigen-specific T-cell activation, need to be satisfied to achieve the optimal adaptive response. As such, we elucidate the current landscape and future directions of work on biomarkers for the prediction of ICI efficacy, focusing on the mechanisms of tumor immune escape, the composition and activity of the immune system in the tumor, the foreignness of the tumor, and host factors.

\section{Mechanisms of tumor immune escape}

To date, the detection of PD-L1 expression by immunohistochemistry (IHC) has been the most widely used clinical approach to predicting the efficacy of PD-1/PD-L1 inhibitors. $^{22}$ The FDA has approved the use of a relevant antibody (22c3) to quantify PD-L1 expression in tumor cells by IHC in NSCLC. An expression level $>50 \%$ is required for using pembrolizumab in the first-line setting. ${ }^{23}$ Regarding the target of PD-1/PD-L1 inhibitors, patients with high PD-L1 expression are expected to be more responsive to these inhibitors. Many studies have shown that both the objective response rate (ORR) and the overall survival (OS) of PDL1-positive patients after ICI therapy were higher than those of PD-L1-negative patients. ${ }^{15,24,25}$ Recently, atezolizumab was shown to result in a significant improvement in OS compared with docetaxel in stage IIIB or IV NSCLC (OAK trial), and patients with high levels of PD-L1 ( $\geq 50 \%$ on tumor cells or $\geq 10 \%$ on tumor-infiltrating lymphocytes [TILs]) derived the greatest benefit from atezolizumab. ${ }^{24}$ In particular, the comparison between the Keynote 024 and Checkmate 026 clinical trials further suggested the significance of high PD-L1 expression in predicting the efficacy of the first-line treatment of metastatic NSCLC. ${ }^{26-28}$

However, there are many challenges related to using PD-L1 expression as a prediction biomarker. First, no definitive conclusion has been drawn regarding the association between PD-L1-positive tumors and ICI efficacy, and some contradictory results have even been obtained in some cancers, such as RCC, MM, and urothelium carcinoma. 13,16,17,29-31 Chae et $\mathrm{al}^{32}$ performed a combined analysis of studies on ICI therapy biomarkers in NSCLC and concluded that there was still no consensus on the use of PD-L1 expression as an ideal marker for patient selection. Additionally, PD-L1-negative patients can still benefit from anti-PD-1/PD-L1 therapy. Taking the findings of the studies performed to date into consideration, it was shown that using only PD-L1 expression levels for the prediction of ICI efficacy is insufficient. Moreover, because of differences in the biological characteristics of tumors at different locations and the different types of antibodies used in IHC, it is more difficult to develop uniform IHC criteria for PD-LI evaluation. ${ }^{33}$ Owing to the limitation presented by the semi-quantitative nature of $\mathrm{IHC}$, some researchers used the Her-2 detection method in breast cancer to propose combining IHC and gene amplification to achieve qualitative and quantitative unification. ${ }^{34}$ In this regard, Inoue et $\mathrm{al}^{35}$ retrospectively analyzed 654 postoperative NSCLC patients and showed that the gene amplification number of $P D-L 1$ could be used as a supplemental or alternative biomarker of PD-L1 expression. Additionally, PD-L1 expression in tumor cells and immune cells is a dynamic process. Thus, the detection of PD-L1 expression occurring at a particular point in time may be insufficient. ${ }^{36}$ Furthermore, the heterogeneity of PD-L1 expression in the same tumor tissue and between primary lesions and different metastatic tumors in the same patient also increases the difficulty of assessing PD-L1 expression levels. ${ }^{37,38}$ The details of PD-L1 detection in large Phase III trials performed to date are summarized in Table 1. However, the differences in their conclusions regarding PD-L1 expression and efficacy are probably related not only to the method of performing the PD-L1 assay but also to the complex interactions between tumors and the immune 


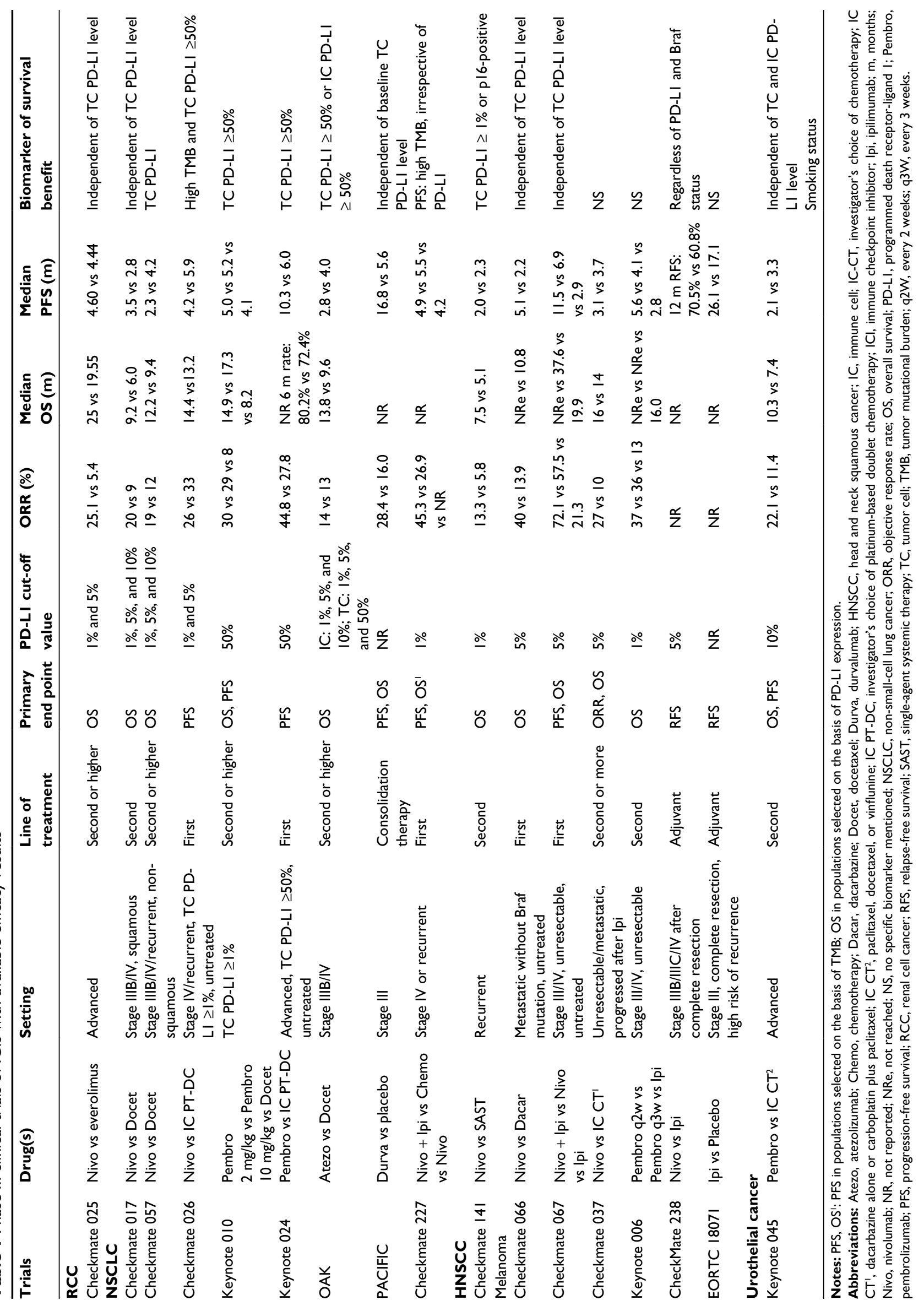


system, which along with tumor mutation burden (TMB) have been revealed as other potential biomarkers.

\section{CTLA-4 and PD-L2}

Associations of other immunosuppressive molecules with the rate of response to ICI treatment have also been reported. It has been shown that the CTLA-4 mRNA expression level before treatment is correlated with the efficacy of both the anti-CTLA-4 antibody and the anti-PD-L1 antibody, which might be associated with the promotion of the inhibitory function by Tregs on Teffs via CTLA-4 in TME; however, this inhibitory function was weaker than that of PD-L1.,39,40 Moreover, Yearley et $\mathrm{al}^{41}$ reported that PD-L2 status was also a significant predictor of progression-free survival (PFS) with pembrolizumab and that it operated independently of PD-L1 status in HNSCC. Although there are some limitations, tumor immune escape clearly plays a critical role in the mechanism of immune action and in the prediction of the biomarkers of ICIs.

\section{Immune composition and activity in tumors}

\section{Tumor immunophenotypes}

Chen et $\mathrm{l}^{42}$ identified three tumor immunophenotypes: immune-inflamed, immune-excluded, and immune-desert phenotypes. Tumors with the immune-inflamed phenotype show immune cell infiltration at the tumor edge or in the tumor stroma, which is regarded as reflecting an inflammatory tumor. In this type of tumor, immune responses can be suppressed by the expression of immune checkpoints. ${ }^{42}$ Therefore, ICIs can unleash the suppressed immunity and have better efficacy. The latter two types are non-inflammatory tumors. Owing to steric hindrance, effective immune responses are lacking inside these tumors; therefore, the function of ICIs is very limited in such cases. The classification of the above-mentioned immunophenotypes is based on the differences in the infiltration patterns of immune cells inside tumors. The proposed immunophenotypes provide a basis for personalized tumor immunotherapy. However, some immune-inflamed tumors may also not respond to ICIs, partly because the early Treg recruitment inhibits an effective antitumor immune response. ${ }^{43}$ Additionally, several factors that influence immunophenotypes, such as TMB and the tumor microbial spectrum, might become biomarkers for the prediction of ICI efficacy. ${ }^{42}$ Page et al ${ }^{44}$ proposed that T-cell receptor (TCR) sequencing can provide additional information on TIL number and clonal diversity. The combination of TCR sequencing and IHC can assess TILs more comprehensively and accurately. However, these immunophenotypes focus on the numbers and aggregation patterns of TILs and ignore TIL functions. The use of a multi-parameter flow cytometer for the analysis of markers of TIL activation and depletion can compensate for this deficiency. Daud et $\mathrm{a}^{45}$ analyzed $40 \mathrm{MM}$ patients at the progressive stage treated with nivolumab or pembrolizumab and found that patients with CTLA- $4{ }^{\text {high }}$ PD$1^{\text {high }}$ expression in more than $20 \%$ of CD $8+$ TILs had a better prognosis. Interestingly, the improved prognosis linked to ICI therapy was associated only with the CTLA- $4^{\text {high}} \mathrm{PD}-1^{\text {high }}$ double-positive population and was not associated with the single-positive one. ${ }^{45}$ Other important biomarkers of exhaustion, including TIM-3, LAG-3, and VISTA, are usually coexpressed with PD-1 in excessively exhausted Teff cells. ${ }^{42,46}$ $\mathrm{T}$ cells that express many types of exhaustion/activation markers usually show a poor response to anti-PD-1/PD-L1 treatment. ${ }^{42}$ The effects of the TIL infiltration patterns and exhaustion/activation markers on ICI efficacy require further studies with large sample sizes.

\section{Immunosuppressive factors in TME}

Some studies have shown that immunosuppressive factors, particularly Tregs in TME, are potentially involved in the lack of response to ICIs in specific subtypes of cancer that are heavily infiltrated with adaptive immune cells. ${ }^{43,47,48}$ Enhancing the immune response to these tumors by depleting Tregs in addition to immune checkpoint inhibition impaired tumor growth and prolonged survival. ${ }^{43}$ As Lowther et al ${ }^{49}$ showed that PD-1-high Tregs in the TME and circulating blood were an exhausted type, it is reasonable to speculate that the function of ICIs may be impaired if PD-1 was preferentially expressed on these cells or if these Tregs were activated in the presence of ICIs. ${ }^{43}$ In contrast, in an earlier Phase II trial of melanoma patients treated with ipilumab, higher infiltration of Foxp3+Tregs at baseline was significantly positively associated with clinical outcome. ${ }^{50}$. More research on baseline Treg infiltration and the role of immune checkpoints on Tregs, such as CTLA-4 and PD-L1, is warranted. Some studies also showed that the depletion of Tregs during ICI treatment may be associated with ICI efficacy. ${ }^{51,52}$ Although some studies showed that eradicating or reprogramming other immunosuppressive factors, such as myeloid-derived suppressor cells (MDSCs), $\gamma \delta \mathrm{T}$ cells, and macrophages, could enhance clinical responses to ICI treatment, few studies have demonstrated whether they can be a biomarker for predicting its efficacy. ${ }^{48}$ 


\section{Inflammatory gene signature}

Inflammatory cells and proteins can participate in tumor metastasis, tumor growth, and angiogenesis..$^{53}$ Moreover, in some tumors, PD-L1 is not constitutively expressed but rather is induced in response to inflammatory signals produced by an active anti-tumor immune response, with expression induced on most tumor cells in response to IFN- $\gamma{ }^{54,55}$ This interactive function allows Inflammatory gene signatures to be used as ICI biomarkers to select appropriate patient populations. ${ }^{56}$ Ribas et al indicated that IFN- $\gamma$ signaling-related genes may allow the improved selection of patients likely to respond to anti-PD-1 therapy with pembrolizumab. ${ }^{57}$ In the exploratory analysis of the POPLAR study, patients with high Teff-IFN- $\gamma$-associated gene expression had improved OS with atezolizumab. ${ }^{25}$ Additionally, several studies showed that the loss of IFN- $\gamma$ signaling in tumor cells may represent a common mechanism for tumor resistance to ICIs. ${ }^{58-60}$ These studies indicated that consideration of the characteristics of IFN- $\gamma$-related genes in tumors would be useful in the ICI prognosis model.

\section{Tumor foreignness}

\section{Tumor mutation spectrum and mutation burden}

TMB refers to the number of somatic cell mutations in the tumor genome after removing germline mutations. Many studies have explored the association between TMB and ICI efficacy (Table 2). ${ }^{27,61-68}$ Patients with a high TMB had significantly higher response rates, and longer PFS and OS than those with a lower TMB. Notably, most of these studies were retrospective and tested old biopsy specimens, which may not accurately reflect the current mutational burden of a tumor. Recently, Checkmate 227 showed that, in patients with advanced NSCLC and a tumor mutational burden of $\geq 10$ per megabase, first-line treatment with nivolumab plus ipilimumab was associated with longer PFS than chemotherapy. ${ }^{67}$ These results indicate that TMB is an important and independent biomarker in advanced NSCLC. Some other studies may indirectly support the use of TMB as a biomarker of ICI efficacy. For example, in studies about NSCLC and urothelial cancer, higher response rates were seen in current and former smokers than in non-smokers, which may be suggestive of the role played by a high mutational load. ${ }^{67,69,70}$ A comparison among different types of tumors showed that tumors with higher TMB, such as MM, HNSCC, and bladder cancer, have a good effect on ICI therapy, with a response rate of more than $15 \% .^{39,71,72}$ Tumors with low TMB, such as pancreatic cancer and prostate cancer, have a poor response to ICI therapy. ${ }^{19} \mathrm{TMB}$ can thus be used for cross-sectional analyses across many types of tumor to identify the patient population that can benefit from immunotherapy. However, TMB also has its limits. First, cancers are not static and can acquire mutations as they evolve. Issues related to the need for the dynamic monitoring of TMB and the timing required to detect TMB warrant further exploration. Second, immunogenic antigen expression is a necessary - but not a sufficient - condition for immune responses. Therefore, TMB can predict only the effectiveness of ICIs to some extent, and not all patients with high TMB can obtain obvious benefits after ICI therapy (immune tolerance might be caused by mechanisms other than PD-1/PD-L1 and CTLA-4) ${ }^{73}$ Moreover, the effect of ICIs on some patients with a low mutation burden is not poor (the recognition of DNA damage-induced neoantigens by $T$ cells is a relatively random process, and low mutation burden sometimes also produces strong neoantigens). Furthermore, a recent study suggested that not all neoantigens are positively correlated with prognosis. McGranahan et $\mathrm{al}^{74}$ showed that the percentage of clonal neoantigens was positively correlated with ICI efficacy in lung adenocarcinoma, whereas the percentage of subclonal neoantigens was negatively correlated with efficacy. Therefore, if the majority of mutations were subclonal mutations, the presence of high TMB may not predict treatment efficacy. Thus, further classification of neoantigens might be necessary. TMB also has some problems, such as an unclear cut-off value, tumor heterogeneity, high cost of next-generation sequencing, and complicated data analysis. Nevertheless, a number of studies on the use of TMB as a biomarker for the prediction of ICI efficacy are now underway. The findings obtained thus far suggest the potential for including TMB analysis in the stratification of ICI clinical trials.

\section{Mismatch repair deficiency (dMMR)}

As with TMB, dMMR has recently become a marker for the prediction of ICI efficacy. Beyond the context of colorectal cancer, Le et $\mathrm{a}^{75}$ expanded the application of dMMR across 12 different tumor types; in this study, $53 \%$ of patients showed an objective response, and $21 \%$ achieved a complete response. In May 2017, the FDA has approved pembrolizumab for the treatment of adult and pediatric cancers that progressed after prior treatment, which are dMMR or microsatellite instability high, irrespective of tumor type ${ }^{76} \mathrm{DNA}$ mismatch repair (MMR) is a critical mechanism in DNA repair. Its major function is to proofread mismatched bases in a timely manner to maintain genome stability. ${ }^{77}$ dMMR results in many mutations that enhance tumor immunogenicity and induce more active immune responses.$^{78}$ Additionally, 
Table 2 Studies utilizing TMB as a predictor of response to treatment with ICls

\begin{tabular}{|c|c|c|c|c|c|}
\hline \multicolumn{6}{|l|}{ Clinical trials } \\
\hline \multicolumn{6}{|c|}{ Prespecified analysis } \\
\hline Study & Drug & $\begin{array}{l}\text { Tumor type and } \\
\text { stage }\end{array}$ & $\begin{array}{l}\text { Calculation } \\
\text { methodology for } \\
\text { TMB }\end{array}$ & Cut-off & Results \\
\hline $\begin{array}{l}\text { Checkmate } \\
227^{67}\end{array}$ & Nivo + Ipi & $\begin{array}{l}\text { Stage IV or } \\
\text { recurrent } \\
\text { NSCLC }\end{array}$ & $\begin{array}{l}\text { CGP (Foundation } \\
\text { Medicine) }\end{array}$ & 10 per $\mathrm{Mb}$ & $\begin{array}{l}\text { In patients with high TMB ( } \geq 10 \text { per Mb), } \\
\text { median PFS: } 7.2 \mathrm{~m} \text { vs } 5.5 \mathrm{~m} \text { (Nivo + Ipi } \\
\text { vs Chemo) }\end{array}$ \\
\hline \multicolumn{6}{|c|}{ Exploratory analysis } \\
\hline Study & Drug & $\begin{array}{l}\text { Tumor type and } \\
\text { stage }\end{array}$ & $\begin{array}{l}\text { Calculation } \\
\text { methodology for } \\
\text { TMB }\end{array}$ & Cut-off & Results \\
\hline IMvigor $210^{68}$ & Atezo & $\begin{array}{l}\text { Locally } \\
\text { advanced and } \\
\text { metastatic UC }\end{array}$ & $\begin{array}{l}\text { CGP (Foundation } \\
\text { Medicine) }\end{array}$ & & $\begin{array}{l}\text { Median TMB: I } 2.4 \text { vs } 6.4 \text { per Mb } \\
\text { (responders vs non-responders) }\end{array}$ \\
\hline $\begin{array}{l}\text { Checkmate } \\
026^{27}\end{array}$ & Nivo & $\begin{array}{l}\text { Stage IV or } \\
\text { recurrent } \\
\text { NSCLC }\end{array}$ & WES & $\begin{array}{l}\text { Low TMB: } 0-100 \\
\text { mutations } \\
\text { Medium TMB: } 100-242 \\
\text { mutations } \\
\text { High TMB: } \geq 243 \text { mutations }\end{array}$ & $\begin{array}{l}\text { Among the patients with a high TMB, } \\
\text { RR: } 47 \% \text { vs } 28 \% \text {, } \\
\text { median PFS } 9.7 \mathrm{~m} \text { vs } 5.8 \mathrm{~m} \\
\text { (Nivo vs Chemo) }\end{array}$ \\
\hline \multicolumn{6}{|c|}{ Retrospective study } \\
\hline Author & Drug & $\begin{array}{l}\text { Tumor type and } \\
\text { stage }\end{array}$ & $\begin{array}{l}\text { Calculation } \\
\text { methodology for } \\
\text { TMB }\end{array}$ & Results & \\
\hline $\begin{array}{l}\text { Campesato } \\
\text { et al }{ }^{66}\end{array}$ & Pembro & NSCLC & $\begin{array}{l}\text { CGP (Foundation } \\
\text { Medicine) }\end{array}$ & $\begin{array}{l}\text { TMB was calculated using ju } \\
\text { gene panel } \\
\text { High TMB vs low TMB: } 69 \% \\
\text { experiencing durable clinica }\end{array}$ & $\begin{array}{l}\text { t mutated genes present in the cancer } \\
\text { vs } 20 \% \text { (proportions of patients } \\
\text { benefit) }\end{array}$ \\
\hline Rizvi et al ${ }^{65}$ & Pembro & NSCLC & WES & $\begin{array}{l}\text { Higher somatic nonsynonyn } \\
\text { the clinical efficacy of Pemb } \\
\text { Median number of nonsyno } \\
\text { with durable clinical benefit }\end{array}$ & $\begin{array}{l}\text { ous mutation burden was associated with } \\
\text { ymous mutations: } 302 \text { vs I } 48 \text { (patients } \\
\text { s no durable benefit) }\end{array}$ \\
\hline Johnson et a ${ }^{64}$ & $\begin{array}{l}\text { Nivo or Pembro } \\
\text { or Atezo }\end{array}$ & Melanoma & $\begin{array}{l}\text { CGP (Foundation } \\
\text { Medicine) }\end{array}$ & $\begin{array}{l}\text { Mutational load effectively s } \\
\text { Median TMB: } 45.6 \text { vs } 3.9 \text { pe } \\
\text { Median PFS: not reached vs } \\
\text { Median OS: not reached vs } \\
\text { intermediate-TMB group vs }\end{array}$ & $\begin{array}{l}\text { ratified patients by likelihood of response } \\
\text { Mb (responders vs non-responders) } \\
39 \text { days vs } 86 \text { days } \\
00 \text { days vs } 375 \text { days (high-TMB group vs } \\
\text { ow-TMB group) }\end{array}$ \\
\hline $\begin{array}{l}\text { Yaghmour } \\
\text { et } \mathrm{a}^{63}\end{array}$ & $\begin{array}{l}\text { Ipi or Pembro or } \\
\text { Nivo }\end{array}$ & Any solid tumor & Not mentioned & $\begin{array}{l}\text { Higher TMB was associated } \\
\text { OS: } 722 \text { vs } 432 \text { days } \\
\text { OR: } 50 \% \text { vs } 20 \% \\
\text { (high-TMB group vs low-TN }\end{array}$ & $\begin{array}{l}\text { with improved OS } \\
3 \text { group) }\end{array}$ \\
\hline $\begin{array}{l}\text { Kowanetz } \\
\text { et al }\left.\right|^{61}\end{array}$ & Atezo & NSCLC & $\begin{array}{l}\text { CGP (Foundation } \\
\text { Medicine) }\end{array}$ & $\begin{array}{l}\text { OS, PFS, and RR were impr } \\
\text { treated with Atezo in both }\end{array}$ & $\begin{array}{l}\text { ved in patients with increased TMB } \\
\text { nselected and selected patients }\end{array}$ \\
\hline $\begin{array}{l}\text { Goodman } \\
\text { et } \mathrm{al}^{62}\end{array}$ & $\begin{array}{l}\text { anti-PD-I/ PD-LI, } \\
\text { anti-CTLA-4, } \\
\text { anti-CTLA-4 + } \\
\text { anti-PD-I/PD-LI, } \\
\text { high-dose IL-2, } \\
\text { and other agents' }\end{array}$ & $\begin{array}{l}\text { Melanoma, } \\
\text { NSCLC, and } \\
\text { other types }\end{array}$ & $\begin{array}{l}\text { CGP (Foundation } \\
\text { Medicine) }\end{array}$ & $\begin{array}{l}\text { Higher TMB was independe } \\
\text { parameters } \\
\text { RR: } 58 \% \text { vs } 20 \% \\
\text { Median PFS: } 12.8 \text { m vs } 3.3 \mathrm{n} \\
\text { Median OS: not reached vs } \\
\text { (high vs low-to-intermediat }\end{array}$ & $\begin{array}{l}\text { tly associated with better outcome } \\
6.3 \mathrm{~m} \\
\text { TMB) }\end{array}$ \\
\hline
\end{tabular}

Notes: 'Other agents: OX40, anti-CD73, talimogene laherparepvec, OX40 + anti-PD-LI, and IDO + anti-PD-I. ${ }^{2}$ Tumors included the following: adrenal carcinoma, appendix adenocarcinoma, basal cell carcinoma, bladder transitional cell carcinoma, breast cancer, cervical cancer, colon adenocarcinoma, cutaneous squamous cell carcinoma, hepatocellular carcinoma, head and neck, Merkel cell carcinoma, ovarian carcinoma, pleural mesothelioma, prostate cancer, renal cell carcinoma, sarcoma, thyroid cancer, unknown primary squamous cell carcinoma, and urethral squamous cell carcinoma

Abbreviations: Atezo, atezolizumab; Chemo, chemotherapy; CTLA-4, cytotoxic T-lymphocyte-associated antigen-4; CGP, comprehensive genomic profiling; ICI, immune checkpoint inhibitor; Ipi, ipilimumab; m, months; Mb, megabase; Nivo, nivolumab; NSCLC, non-small-cell lung cancer; Pembro, pembrolizumab; OR, odds ratio; OS, overall survival; PD-I, programmed death receptor-I; PD-LI, programmed death receptor-ligand I; PFS, progression-free survival; RR, response rate; SCLC, small-cell lung cancer; TMB, tumor mutational burden; UC, urothelial carcinoma; WES, whole-exome sequencing. 
some studies have also confirmed that mutations in other genes involved in the DNA replication repair process (e.g., the POLE gene) are associated with ICI prognosis. ${ }^{79}$ However, individuals with dMMR account for only a small percentage of patients. Some patients with a proficient MMR system can still benefit from ICI therapy. ${ }^{80}$

\section{Expression of viral genes}

Recently, the association between the PD-1-PD-L1 pathway and virus infection in certain tumors, such as HPV-induced cervical cancer and HNSCC, and EBV-induced gastric cancer and nasopharyngeal carcinoma, has elicited considerable attention. First, PD-L1 expression is thought to play a role in the initiation and persistence of HPV infection by providing an immune-privileged site where T-cell activity is downregulated. ${ }^{81-83}$ Second, viral antigens that will generally not be lost or downregulated can trigger an immune response due to their exogenous nature. Moreover, virally mediated tumors develop in the context of chronic infection in which immune checkpoints may be activated over time. Many studies have demonstrated the positive correlation between PD-L1 expression and virus infection in various cancers, including HNSCC, cervical cancer, and EBV-induced malignant tumors. ${ }^{81,84-87}$ Additionally, recent studies have shown that more T-cell infiltration was observed in virus-positive tumors than in the same type of virus-negative ones. ${ }^{88}$

At present, study reports about ICI efficacy are limited to HNSCC. Both Keynote 012 and Checkmate 141 showed that HPV-positive tumors obtained more benefits from ICIs than HPV-negative ones. ${ }^{15,89}$ Data were insufficient in other types of virus-infected tumors, such as HPV-infected cervical cancer and EBV-induced malignant tumors. Keynote 028 showed the antitumor activity of pembrolizumab in PD-L1-positive cervical cancer, but it did not evaluate the association between the efficacy of pembrolizumab and HPV infection. ${ }^{83} \mathrm{On}$ the other hand, the preliminary results of Checkmate 358 showed that a response to nivolumab was observed regardless of PD-L1 or HPV status. ${ }^{90}$ However, Checkmate 358 is a Phase I/II study including only 24 patients, the final results of which are yet to be published. ${ }^{90}$ Further evaluation of the role of virus infection in ICI efficacy should be performed.

\section{Driver gene mutation}

Not all kinds of tumor cell gene mutations can enhance TILmediated immune responses. Recent studies have shown that tumor-associated driver gene mutations not only fail to enhance but also actually attenuate immune responses. The subgroup analysis in the Checkmate 057 trial showed that
NSCLC patients with EGFR mutations or ALK rearrangements obtained relatively minor benefits from ICI therapy. ${ }^{10}$ Currently, the mechanism underlying the effects of driver gene mutations on tumor local immunity and ICI efficacy is still unclear. It is speculated that tumors with driver gene mutations might have lower total mutation levels due to the lower mutation heterogeneity. A retrospective study showed that fewer NSCLC patients with EGFR mutations or ALK rearrangements exhibited both positive PD-L1 expression and high CD8+TIL infiltration. ${ }^{91}$ Moreover, individuals with EGFR mutations with non-T790M-acquired drug resistance might benefit more from PD-1 inhibitors than patients with T790M-acquired drug resistance. ${ }^{92}$ Based on these observations, recent studies on EGFR mutations have mainly adopted therapy of ICIs combined with tyrosine kinase inhibitors. ${ }^{93}$ Although the Checkmate 142 trial showed that KRAS or BRAF mutations did not affect the efficacy of PD-1 inhibitors, some studies showed that KRAS and BRAF mutations or other mutations in the MAPK pathway attenuated immunity by reducing the transcription of major histocompatibility complex class I (MHC I) molecules. ${ }^{94-96}$ Additionally, $\beta$-catenin pathway activation and the direct or indirect loss of PTEN resulted in the reduction of CD8+TILs infiltration in melanoma. ${ }^{97,98}$ The effects of driver gene mutations on the immune microenvironment and on the efficacy of immunotherapy still require further research.

In summary, the T-cell immune response is closely associated with the increase of neoantigens that results from DNA damage, or repair system defects, and foreign antigens expressed by viral genes. DNA and RNA sequencing plays an important role in the evaluation of the tumor foreignness and can optimize the selection of patients for ICI therapy. However, the presence of immunogenic antigens is only one of the necessary conditions of immune responses in tumors. Furthermore, the effects of driver gene mutations on the immune microenvironment and the efficacy of immunotherapy are more complicated. Most studies have shown that, in patients with driver gene mutations, ICIs have poor efficacy. The use of ICIs combined with corresponding targeted therapy is a promising direction of future research for the treatment of these patients.

\section{Host factors}

\section{Peripheral blood markers}

Several studies have reported that the absolute counts of certain cell populations in peripheral blood (e.g., lymphocytes, monocytes, and neutrophils) were associated with ICI efficacy ${ }^{99-106}$ However, some other studies cast doubt on this. 
Sun et $\mathrm{al}^{107}$ reviewed all consecutive patients treated with antiPD-1/PD-L1 monotherapy in Phase I trials performed at our institution between December 2011 and January 2014 and found that baseline absolute lymphocyte count (ALC) was not associated with response to anti-PD-1/PD-L1; thus, patients should not be excluded from early-phase clinical trials testing immune checkpoint blockers because of ALC. Additionally, a study by Subrahmanyam et $\mathrm{al}^{108}$ also did not find that lymphocyte and monocyte frequencies had predictive value for ICI efficacy. However, they found differences in CD4+ and CD8+ memory T-cell subsets between responders and non-responders to anti-CTLA-4 and differences in specific NK cell subsets (CD69+ and MIP1 $\beta+$ NK cell populations) in responders and non-responders to anti-PD-1. The distinct sets of candidate biomarkers for anti-CTLA-4 and anti-PD-1 therapies may be attributable to the different sites at which they function. ${ }^{4}$ Moreover, some other subsets in peripheral blood, such as circulating MDSCs and CD14+CD16-HLA-DRhi monocytes, were reported as predictors of ICI efficacy. ${ }^{109,110}$ At present, the evidence that subsets of circulating blood cells can be used as predictors of ICI efficacy remains insufficient and this issue warrants further research.

Apart from these circulating immune cells, peripheral blood TCR diversity also plays an important role in CTLA-4 inhibitor therapy. CTLA-4 inhibitors can promote reconstruction of the TCR repertoire and increase its diversity. ${ }^{11-113}$ Cha et $\mathrm{al}^{111}$ showed that the maintenance of high-frequency TCR clonotypes was associated with longer OS in patients following ipilimumab therapy; however, patients who lost more high-frequency clonotypes usually had shorter OS. These high-frequency TCR clonotypes might represent high-affinity T cells associated with anti-tumor responses. ${ }^{11}$ Notably, Huang et $\mathrm{al}^{114}$ recently developed a "reinvigoration score" by relating changes in circulating exhausted-phenotype CD8+ $\mathrm{T}$ cells to tumor burden to predict anti-PD-1 response. They found that these responding exhausted-phenotype CD8+ $\mathrm{T}$ cells in the blood contained TCR clonotypes shared with TILs, which may be the factor underlying this phenomenon. However, immune cell functions in TME clearly differ markedly from those in peripheral blood.

\section{Genotypes of patients}

Genotype may affect ICI efficacy; however, current evidence is limited to studies with small samples. Queirolo et al ${ }^{115}$ analyzed $14 \mathrm{MM}$ patients and found that the rate of response to ipilimumab was higher in patients with CTLA- 4-1577G/A and CT60G/A heterozygous genotypes. Another earlier study on the treatment of melanoma using ipilimumab showed that three types of CTLA-4 single-nucleotide polymorphisms (SNPs) (rs4553808, rs11571327, and missense SNP rs231775) were associated with the response to anti-CTLA4-specific antibodies. ${ }^{116}$ However, a Phase II clinical trial of MM did not reveal an association between CTLA-4 SNPs and treatment response. ${ }^{50}$ Therefore, the association between SNPs and ICI efficacy still requires further verification.

\section{Microbial spectrum}

Several studies have demonstrated that manipulation of the microbiota may modulate the effect of cancer immunotherapy. ${ }^{117-119}$ For example, the transplantation of fecal microbiota from cancer patients who responded to ICI into germ-free or antibiotic-treated mice was reported to ameliorate the anti-tumor effects of ICIs. ${ }^{11-119}$ Moreover, Matson et al ${ }^{120}$ recently analyzed baseline stool samples from MM patients before immunotherapy treatment and observed a significant association between commensal microbial composition and clinical response. Bacterial species that were more abundant in responders included Bifidobacterium longum, Collinsella aerofaciens, and Enterococcus faecium. ${ }^{120}$ Similar to the previously mentioned results, Chaput et al ${ }^{121}$ suggested that baseline gut microbiota enriched with Faecali bacteria and other Firmicutes is associated with a beneficial clinical response to ipilimumab. The search is underway for components of the microbiota that enhance the action of other immunotherapies. Discovery of the effect of gut microbiota on ICI efficacy has clearly opened up another direction for ICI biomarker discovery.

Overall, although some inspiring results have been obtained, few studies on host factors such as peripheral blood markers, gene polymorphisms, and gut microbiota have been performed thus far, and this work is still at the exploratory stage. It is challenging to identify the factors that actually predict treatment response and to separate them from the confounding factors.

\section{Conclusion}

Our analyses showed that the main functions of ICIs are to unleash immune tolerance, which results from the activation of immune checkpoint pathways. The effectiveness of these therapies requires cooperation with all other aspects of the immune system. First, the expression of immunogenic antigens on tumor cells is an essential condition for the induction of anti-tumor immune responses. Therefore, evaluation of the tumor foreignness using methods such as gene analysis is necessary. Second, immune activities in the TME include the distribution and function of TILs and inflammatory gene expression and are also associated with ICI efficacy. Third, 


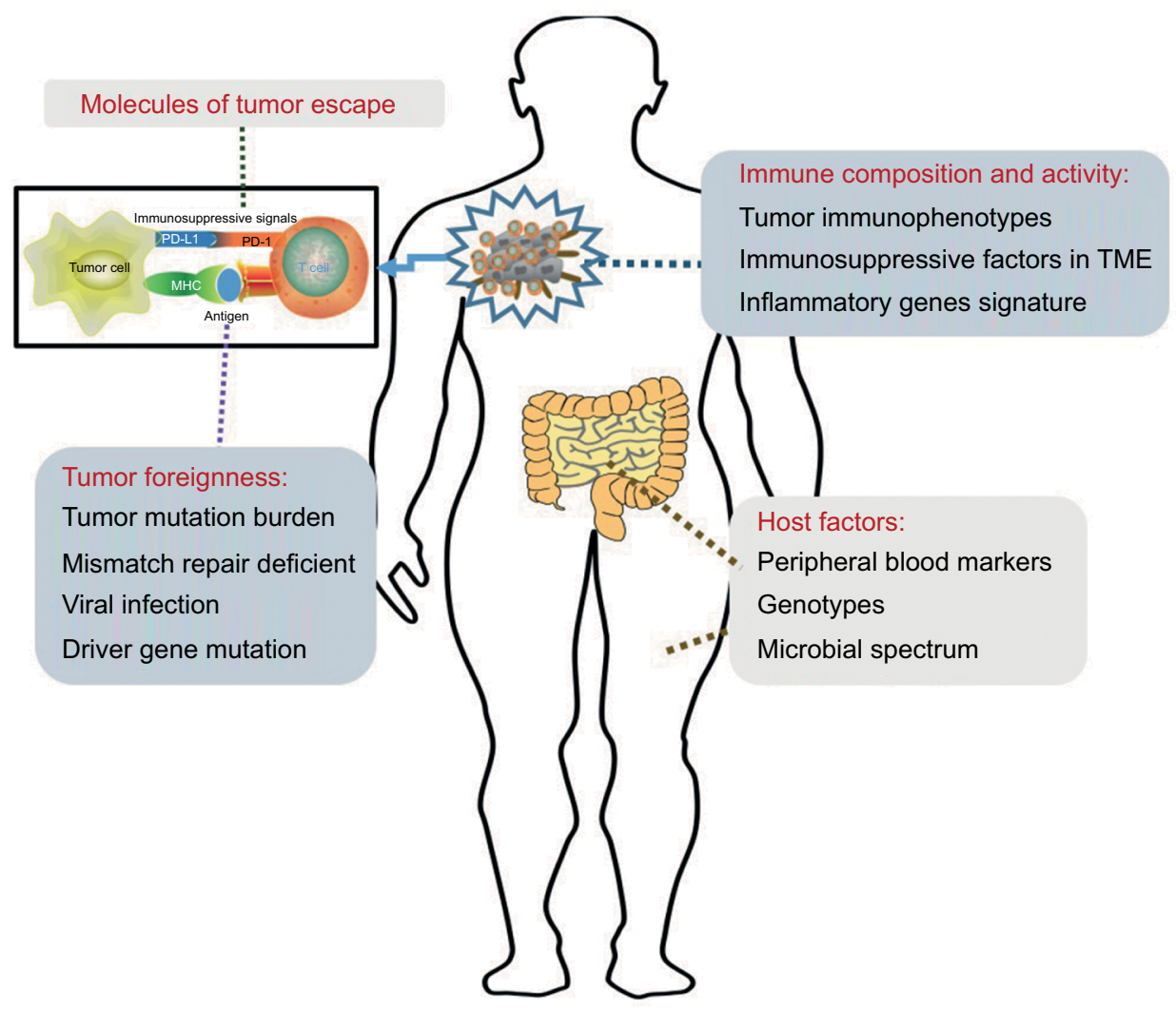

Figure 2 Graphical representation of distinct biomarkers for patient selection for treatment with immune checkpoint inhibitors.

Notes: Sensitivity to immune checkpoint inhibition is influenced by the following four variables: the molecules involved in tumor immune escape, the foreignness of the tumor, the composition and activity of the immune system in tumors, and host factors. As these four may be used in combination to determine the likelihood that an individual patient will respond to treatment, they are potential guides for treatment decisions.

Abbreviations: MHC, major histocompatibility complex; PD-I, programmed death receptor-I; PD-LI, programmed death receptor-ligand I; TME, tumor microenvironment.

the specific mechanisms of tumor escape also play important roles in the effectiveness of ICIs. The detection of PD-L1 might require the use of combined measures. Furthermore, studies on peripheral blood markers, gene polymorphisms, and gut microbiota are still at an initial stage. These four classification methods provide a framework for our studies on ICI biomarkers (Figure 2).

It is worth noting that the majority of the aforementioned factors were used as solitary subjects of study in most previous studies, especially in large Phase III trials (Table 1). The fact that most of them focused only on PD-L1 expression may have been due to the early stage at which these studies were performed. Few studies on their association and weights have been performed. The cancer immunogram proposed by Blank et al ${ }^{122}$ is an approach involving the use of the above-mentioned methods, including many types of prediction markers, to predict ICI efficacy. It is imperative to perform multivariate predictive analyses that include tumor foreignness, immune composition, immune activity, tumor escape mechanisms, and some host factors. Additionally, many measures, including quantitative genetic analysis, IHC to determine the density and location of immune cell types, and flow cytometry for various cell surface markers, can be combined with some conventional laboratory examinations. With the implementation of large-scale ICI clinical studies and the emergence of some promising results, multivariate analyses can help us to optimize patient selection and possibly personalize cancer treatment using ICIs.

\section{Acknowledgments}

This work was supported by the grants from the Shandong Provincial Natural Science Foundation (ZR2015HZ004), the National Health and Family Planning Commission of China (201402011), and the National Science Foundation for Young Scientists of China (81602031).

\section{Author contributions}

$\mathrm{YZ}$ and $\mathrm{ZL}$ were responsible for the conception and design of the study. JY and FZ provided useful suggestions. All authors contributed toward data analysis, drafting and critically revising the paper and agree to be accountable for all aspects of the work. All authors read and approved the final manuscript. 


\section{Disclosure}

The authors report no conflicts of interest in this work.

\section{References}

1. Peggs KS, Quezada SA, Chambers CA, Korman AJ, Allison JP. Blockade of CTLA-4 on both effector and regulatory $\mathrm{T}$ cell compartments contributes to the antitumor activity of anti-CTLA-4 antibodies. $J$ Exp Med. 2009;206:1717-1725.

2. Shrikant P, Khoruts A, Mescher MF. CTLA-4 blockade reverses CD8+ $\mathrm{T}$ cell tolerance to tumor by a CD4+ T cell- and IL-2-dependent mechanism. Immunity. 1999;11:483-493.

3. Keir ME, Butte MJ, Freeman GJ, Sharpe AH. PD-1 and its ligands in tolerance and immunity. Annu Rev Immunol. 2008;26:677-704.

4. Mellman I, Coukos G, Dranoff G. Cancer immunotherapy comes of age. Nature. 2011:480:480-489.

5. Hodi FS, O'Day SJ, McDermott DF, et al. Improved survival with ipilimumab in patients with metastatic melanoma. $N$ Engl $J$ Med. 2010; 363:711-723.

6. Robert $\mathrm{C}$, Thomas $\mathrm{L}$, Bondarenko I, et al. Ipilimumab plus dacarbazine for previously untreated metastatic melanoma. $N$ Engl $J$ Med. 2011;364:2517-2526.

7. Robert C, Long GV, Brady B, et al. Nivolumab in previously untreated melanoma without BRAF mutation. $N$ Engl J Med. 2015;372: 320-330.

8. Robert C, Ribas A, Wolchok JD, et al. Anti-programmed-deathreceptor-1 treatment with pembrolizumab in ipilimumab-refractory advanced melanoma: a randomised dose-comparison cohort of a phase 1 trial. Lancet. 2014;384:1109-1117.

9. Weber JS, D'Angelo SP, Minor D, et al. Nivolumab versus chemotherapy in patients with advanced melanoma who progressed after anti-CTLA-4 treatment (CheckMate 037): a randomised, controlled, open-label, phase 3 trial. Lancet Oncol. 2015;16: 375-384.

10. Borghaei H, Paz-Ares L, Horn L, et al. Nivolumab versus docetaxel in advanced nonsquamous non-small-cell lung cancer. $N$ Engl $J$ Med. 2015;373:1627-1639.

11. Brahmer J, Reckamp KL, Baas P, et al. Nivolumab versus docetaxel in advanced squamous-cell non-small-cell lung cancer. $N$ Engl $J$ Med. 2015:373:123-135.

12. Herbst RS, Baas P, Kim DW, et al. Pembrolizumab versus docetaxel for previously treated, PD-L1-positive, advanced non-small-cell lung cancer (KEYNOTE-010): a randomised controlled trial. Lancet. 2016;387;1540-1550.

13. Motzer RJ, Escudier B, McDermott DF, et al. CheckMate, nivolumab versus everolimus in advanced renal-cell carcinoma. $N$ Engl $\mathrm{J}$ Med. 2015:573:1803-1813.

14. Chow LQ, Haddad R, Gupta S, et al. Seiwert, antitumor activity of pembrolizumab in biomarker-unselected patients with recurrent and/or metastatic head and neck squamous cell carcinoma: results from the phase Ib KEYNOTE-012 Expansion Cohort. J Clin Oncol. 2016;34:3838-3845.

15. Ferris RL, Blumenschein G, Jr, Fayette J, et al. Gillison, nivolumab for recurrent squamous-cell carcinoma of the head and neck. $N$ Engl J Med. 2016;375:1856-1867.

16. Apolo AB, Infante JR, Balmanoukian A, et al. Avelumab, an antiprogrammed death-ligand 1 antibody, in patients with refractory metastatic urothelial carcinoma: results from a multicenter, phase $\mathrm{Ib}$ study. J Clin Oncol. 2017;35:2117-2124.

17. Massard C, Gordon MS, Sharma S, et al. Segal, safety and efficacy of durvalumab (MEDI4736), an anti-programmed cell death ligand-1 immune checkpoint inhibitor, in patients with advanced urothelial bladder cancer. J Clin Oncol. 2016;34:3119-3125.

18. Ansell SM, Lesokhin AM, Borrello I, et al. Armand, PD-1 blockade with nivolumab in relapsed or refractory Hodgkin's lymphoma. $N$ Engl J Med. 2015;372:311-319.
19. Lawrence MS, Stojanov P, Polak P, et al. Mutational heterogeneity in cancer and the search for new cancer-associated genes. Nature. 2013;499:214-218.

20. Champiat S, Dercle L, Ammari S, et al. Hyperprogressive disease is a new pattern of progression in cancer patients treated by anti-PD-1/ PD-L1. Clin Cancer Res. 2017;23:1920-1928.

21. FDA alerts healthcare professionals and oncology clinical investigators about two clinical trials on hold evaluating KEYTRUDA $®$ (pembrolizumab) in patients with multiple myeloma. Available from: https://www. fda.gov/Drugs/DrugSafety/ucm574305.htm. Accessed April 1, 2018.

22. Patel SP, Kurzrock R. PD-L1 expression as a predictive biomarker in cancer immunotherapy. Mol Cancer Ther. 2015;14:847-856.

23. Pembrolizumab (KEYTRUDA) Checkpoint Inhibitor. Available from: https:/www.fda.gov/drugs/informationondrugs/approveddrugs/ ucm526430.htm.

24. Rittmeyer A, Barlesi F, Waterkamp D, et al; O.A.K.S. Group. Atezolizumab versus docetaxel in patients with previously treated non-smallcell lung cancer (OAK): a phase 3, open-label, multicentre randomised controlled trial. Lancet. 2017;389:255-265.

25. Fehrenbacher L, Spira A, Ballinger M, et al; P.S. Group. Atezolizumab versus docetaxel for patients with previously treated non-small-cell lung cancer (POPLAR): a multicentre, open-label, phase 2 randomised controlled trial. Lancet. 2016;387:1837-1846.

26. Giroux Leprieur E, Dumenil C, Julie C, et al. Immunotherapy revolutionises non-small-cell lung cancer therapy: results, perspectives and new challenges. Eur J Cancer. 2017;78:16-23.

27. Carbone DP, Reck M, Paz-Ares L, et al. CheckMate, first-line nivolumab in stage IV or recurrent non-small-cell lung cancer. $N$ Engl J Med. 2017;376:2415-2426.

28. Reck M, Rodriguez-Abreu D, Robinson AG, et al. Pembrolizumab versus chemotherapy for PD-L1-positive non-small-cell lung cancer. N Engl J Med. 2016;375:1823-1833.

29. Kee D, McArthur G. Immunotherapy of melanoma. Eur J Surg Oncol. 2017:43:594-603.

30. Balar AV, Galsky MD, Rosenberg JE, et al; I.M.S. Group. Atezolizumab as first-line treatment in cisplatin-ineligible patients with locally advanced and metastatic urothelial carcinoma: a single-arm, multicentre, phase 2 trial. Lancet. 2017;389:67-76.

31. Sharma P, Callahan MK, Bono P, et al. Rosenberg, Nivolumab monotherapy in recurrent metastatic urothelial carcinoma (CheckMate 032): a multicentre, open-label, two-stage, multi-arm, phase 1/2 trial. Lancet Oncol. 2016;17:1590-1598.

32. Chae YK, Pan A, Davis AA, et al. Biomarkers for PD-1/PD-L1 blockade therapy in non-small-cell lung cancer: is PD-L1 expression a good marker for patient selection?. Clin Lung Cancer. 2016;17:350-361.

33. Hansen AR, Siu LL. PD-L1 testing in cancer: challenges in companion diagnostic development. JAMA Oncol. 2016;2:15-16.

34. Meng X, Huang Z, Teng F, Xing L, Yu J. Predictive biomarkers in PD-1/PD-L1 checkpoint blockade immunotherapy. Cancer Treat Rev. 2015;41:868-876.

35. Inoue $Y$, Yoshimura $\mathrm{K}$, Mori $\mathrm{K}$, et al. Sugimura, Clinical significance of PD-L1 and PD-L2 copy number gains in non-small-cell lung cancer. Oncotarget. 2016;7:32113-32128.

36. Mukherji D, Jabbour MN, Saroufim M, et al. Programmed death-ligand 1 expression in muscle-invasive bladder cancer cystectomy specimens and lymph node metastasis: a reliable treatment selection biomarker? Clin Genitourin Cancer. 2016;14:183-187.

37. Callea M, Albiges L, Gupta M, et al. Differential expression of PD-L1 between primary and metastatic sites in clear-cell renal cell carcinoma Cancer Immunol Res. 2015;3:1158-1164.

38. Madore J, Vilain RE, Menzies AM, et al. PD-L1 expression in melanoma shows marked heterogeneity within and between patients: implications for anti-PD-1/PD-L1 clinical trials. Pigment Cell Melanoma Res. 2015;28:245-253.

39. Herbst RS, Soria JC, Kowanetz M, et al. Predictive correlates of response to the anti-PD-L1 antibody MPDL3280A in cancer patients. Nature. 2014;515:563-567. 
40. Van Allen EM, Miao D, Schilling B, et al. Genomic correlates of response to CTLA-4 blockade in metastatic melanoma. Science. 2015;350: 207-211.

41. Yearley JH, Gibson C, Yu N, et al. PD-L2 expression in human tumors: relevance to anti-PD-1 therapy in cancer. Clin Cancer Res. 2017;23:3158-3167.

42. Chen DS, Mellman I. Elements of cancer immunity and the cancerimmune set point. Nature. 2017:541:321-330.

43. Taylor NA, Vick SC, Iglesia MD, et al. Treg depletion potentiates checkpoint inhibition in claudin-low breast cancer. $J$ Clin Invest. 2017;127:3472-3483.

44. Page DB, Yuan J, Redmond D, et al. Deep sequencing of T-cell receptor DNA as a biomarker of clonally expanded TILs in breast cancer after immunotherapy. Cancer Immunol Res. 2016;4:835-844.

45. Daud AI, Loo K, Pauli ML, et al. Tumor immune profiling predicts response to anti-PD-1 therapy in human melanoma. J Clin Invest. 2016;126:3447-3452.

46. Lines JL, Pantazi E, Mak J, et al. VISTA is an immune checkpoint molecule for human T cells. Cancer Res. 2014;74:1924-1932.

47. Takeuchi $Y$, Nishikawa $H$. Roles of regulatory T cells in cancer immunity. Int Immunol. 2016;28:401-409.

48. Li X, Shao C, Shi Y, Han W. Lessons learned from the blockade of immune checkpoints in cancer immunotherapy. J Hematol Oncol. 2018;11:31.

49. Lowther DE, Goods BA, Lucca LE, et al. PD-1 marks dysfunctional regulatory T cells in malignant gliomas. JCI Insight. 2016;1:e85935.

50. Hamid O, Schmidt H, Nissan A, et al. A prospective phase II trial exploring the association between tumor microenvironment biomarkers and clinical activity of ipilimumab in advanced melanoma. JTransl Med. 2011;9:204.

51. Selby MJ, Engelhardt JJ, Quigley M, et al. Anti-CTLA-4 antibodies of IgG2a isotype enhance antitumor activity through reduction of intratumoral regulatory T cells. Cancer Immunol Res. 2013;1:32-42.

52. Simpson TR, Li F, Montalvo-Ortiz W, et al. Fc-dependent depletion of tumor-infiltrating regulatory $T$ cells co-defines the efficacy of antiCTLA-4 therapy against melanoma. J Exp Med. 2013;210;1695-1710.

53. Coussens LM, Werb Z. Inflammation and cancer. Nature. 2002;420: 860-867.

54. Pardoll DM. The blockade of immune checkpoints in cancer immunotherapy. Nat Rev Cancer. 2012;12:252-264.

55. Remon J, Chaput N, Planchard D. Predictive biomarkers for programmed death-1/programmed death ligand immune checkpoint inhibitors in nonsmall cell lung cancer. Curr Opin Oncol. 2016;28:122-129.

56. Parker BS, Rautela J, Hertzog PJ. Antitumour actions of interferons: implications for cancer therapy. Nat Rev Cancer. 2016;16:131-144.

57. Ribas A, Hodi F, Wolchok J, et al. Response to PD-1 blockade with pembrolizumab (MK-3475) is Associated with an interferon inflammatory immune gene signature. In: ASCO Annual Meeting; May 29June 2, 2015: Chicago, Illinois.

58. Benci JL, Xu B, Qiu Y, et al. Tumor interferon signaling regulates a multigenic resistance program to immune checkpoint blockade. Cell. 2016:167:1540-1554 e1512.

59. Zaretsky JM, Garcia-Diaz A, Shin DS, et al. Mutations associated with acquired resistance to PD-1 blockade in melanoma. $N$ Engl J Med. 2016;375:819-829.

60. Gao J, Shi LZ, Zhao H, et al. Loss of IFN-gamma pathway genes in tumor cells as a mechanism of resistance to anti-CTLA-4 therapy. Cell. 2016;167:397-404.e399.

61. Kowanetz M, Shames DS, Cummings C, et al. Tumor mutation load assessed by FoundationOne (FM1) is associated with improved efficacy of atezolizumab (atezo) in patients with advanced NSCLC. Ann Oncol. 2016;27:77P.

62. Goodman AM, Kato S, Bazhenova L, et al. Tumor mutational burden as an independent predictor of response to immunotherapy in diverse cancers. Mol Cancer Ther. 2017;16:2598-2608.

63. Yaghmour G, Pandey M, Ireland C, et al. Role of genomic instability in immunotherapy with checkpoint inhibitors. Anticancer Res. 2016;26:4033-4038.
64. Johnson DB, Frampton GM, Rioth MJ, et al. Targeted next generation sequencing identifies markers of response to PD-1 Blockade. Cancer Immunol Res. 2016; 4:959-967.

65. Rizvi NA, Hellmann MD, Snyder A, et al. Cancer immunology. Mutational landscape determines sensitivity to PD-1 blockade in non-small cell lung cancer. Science. 2015;348:124-128.

66. Campesato LF, Barroso-Sousa R, Jimenez L, et al. Comprehensive cancer-gene panels can be used to estimate mutational load and predict clinical benefit to PD-1 blockade in clinical practice. Oncotarget. 2015;6:34221-34227.

67. Hellmann MD, Ciuleanu TE, Pluzanski A, et al. Nivolumab plus Ipilimumab in lung cancer with a high tumor mutational burden. $N$ Engl $J$ Med. Epub 2018 Apr 16.

68. Rosenberg JE, Hoffman-Censits J, Powles T, et al. Atezolizumab in patients with locally advanced and metastatic urothelial carcinoma who have progressed following treatment with platinum-based chemotherapy: a single-arm, multicentre, phase 2 trial. Lancet. 2016;387:1909-1920.

69. Bellmunt J, de Wit R, Vaughn DJ, et al. Pembrolizumab as secondline therapy for advanced urothelial carcinoma. $N$ Engl J Med. 2017;376:1015-1026.

70. Gettinger SN, Horn L, Gandhi L, et al. Overall survival and long-term safety of nivolumab (anti-programmed death 1 antibody, BMS-936558, ONO-4538) in patients with previously treated advanced non-smallcell lung cancer. J Clin Oncol. 2015;33:2004-2012.

71. Brahmer JR, Tykodi SS, Chow LQ, et al. Safety and activity of antiPD-L1 antibody in patients with advanced cancer. $N$ Engl J Med. 2012;366:2455-2465

72. Topalian SL, Hodi FS, Brahmer JR, et al. Sznol, safety, activity, and immune correlates of anti-PD-1 antibody in cancer. $N$ Engl J Med. 2012;366:2443-2454.

73. Schumacher TN, Schreiber RD. Neoantigens in cancer immunotherapy. Science. 2015;348:69-74.

74. McGranahan N, Furness AJ, Rosenthal R, et al. Clonal neoantigens elicit $\mathrm{T}$ cell immunoreactivity and sensitivity to immune checkpoint blockade. Science. 2016:351:1463-1469.

75. Le DT, Durham JN, Smith KN, et al. Mismatch repair deficiency predicts response of solid tumors to PD-1 blockade. Science. 2017:357:409-413.

76. FDA grants accelerated approval to pembrolizumab for first tissue/ site agnostic indication. Available from: https:/www.fda.gov/drugs/ informationondrugs/approveddrugs/ucm560040.htm. Accessed April 1, 2018.

77. Iyer RR, Pluciennik A, Burdett V, Modrich PL. DNA mismatch repair: functions and mechanisms. Chem Rev. 2006;106:302-323.

78. Smyrk TC, Watson P, Kaul K, Lynch HT. Tumor-infiltrating lymphocytes are a marker for microsatellite instability in colorectal carcinoma, Cancer. 2001;91:2417-2422.

79. Howitt BE, Shukla SA, Sholl LM, et al. Association of polymerase e-mutated and microsatellite-instable endometrial cancers with neoantigen load, number of tumor-infiltrating lymphocytes, and expression of PD-1 and PD-L1. JAMA Oncol. 2015;1:1319-1323.

80. Chen KH, Yuan CT, Tseng LH, Shun CT, Yeh KH. Case report: mismatch repair proficiency and microsatellite stability in gastric cancer may not predict programmed death-1 blockade resistance. $J$ Hematol Oncol. 2016;9:29.

81. Lyford-Pike S, Peng S, Young GD, et al. Evidence for a role of the PD-1:PD-L1 pathway in immune resistance of HPV-associated head and neck squamous cell carcinoma. Cancer Res. 2013;73: 1733-1741.

82. Qin Y, Ekmekcioglu S, Forget MA, et al. Cervical cancer neoantigen landscape and immune activity is associated with human papillomavirus master regulators. Front Immunol. 2017;8:689.

83. Frenel JS, Le Tourneau C, O'Neil B, et al. Varga, safety and efficacy of pembrolizumab in advanced, programmed death ligand 1-positive cervical cancer: results from the phase Ib KEYNOTE-028 trial. J Clin Oncol. 2017;35:4035-4041. 
84. Partlova S, Boucek J, Kloudova K, et al. Distinct patterns of intratumoral immune cell infiltrates in patients with HPV-associated compared to non-virally induced head and neck squamous cell carcinoma. Oncoimmunology. 2015;4:e965570.

85. Mezache L, Paniccia B, Nyinawabera A, Nuovo GJ. Enhanced expression of PD L1 in cervical intraepithelial neoplasia and cervical cancers. Mod Pathol. 201528;1594-1602.

86. Derks S, Liao X, Chiaravalli AM, et al. Abundant PD-L1 expression in Epstein-Barr virus-infected gastric cancers. Oncotarget 2016;7:32925-32932.

87. Ma C, Patel K, Singhi AD, et al. Programmed Death-Ligand 1 Expression Is Common in Gastric Cancer Associated with Epstein-Barr Virus or Microsatellite Instability. Am J Surg Pathol. 2016;40:1496-1506.

88. Rooney MS, Shukla SA, Wu CJ, Getz G, Hacohen N. Molecular and genetic properties of tumors associated with local immune cytolytic activity. Cell. 2015;160:48-61.

89. Seiwert TY, Burtness B, Mehra R, et al. Safety and clinical activity of pembrolizumab for treatment of recurrent or metastatic squamous cell carcinoma of the head and neck (KEYNOTE-012): an open-label, multicentre, phase 1b trial. Lancet Oncol. 2016;17:956-965.

90. Hollebecque A, Meyer T, Moore KN, et al. An open-label, multicohort, phase $1 / 2$ study of nivolumab in patients with virus-associated tumors (CheckMate 358): efficacy and safety in recurrent or metastatic cervical, vaginal, and vulvar cancers. In: Presented at American Society of Clinica Oncology Annual Meeting; June 2-6, 2017; Chicago, IL. Abstract 5504.

91. Gainor JF, Shaw AT, Sequist LV, et al. EGFR mutations and ALK rearrangements are associated with low response rates to PD-1 pathway blockade in non-small cell lung cancer: a retrospective analysis. Clin Cancer Res. 2016;22:4585-4593.

92. Haratani K, Hayashi H, Tanaka T, et al. Tumor immune microenvironment and nivolumab efficacy in EGFR mutation-positive non-smallcell lung cancer based on T790M status after disease progression during EGFR-TKI treatment. Ann Oncol. 2017;28:1532-1539.

93. Tabchi S, Kourie HR, Kattan J. Adding checkpoint inhibitors to tyrosine kinase inhibitors targeting EGFR/ALK in non-small cell lung cancer: a new therapeutic strategy. Invest New Drugs. 2016;34:794-796.

94. Overman MJ, McDermott R, Leach JL, et al. Nivolumab in patients with metastatic DNA mismatch repair-deficient or microsatellite instability-high colorectal cancer (CheckMate 142): an open-label, multicentre, phase 2 study. Lancet Oncol. 2017;18:1182-1191.

95. Bradley SD, Chen Z, Melendez B, et al. BRAFV600E co-opts a conserved $\mathrm{MHC}$ class I internalization pathway to diminish antigen presentation and CD8+ T-cell recognition of melanoma. Cancer Immunol Res. 2015;3:602-609.

96. Atkins D, Breuckmann A, Schmahl GE, et al. MHC class I antigen processing pathway defects, ras mutations and disease stage in colorectal carcinoma. Int J Cancer. 2004;109:265-273.

97. Peng W, Chen JQ, Liu C, et al. Loss of PTEN promotes resistance to T cell-mediated immunotherapy. Cancer Discov. 2016;6:202-216.

98. Spranger S, Bao R, Gajewski TF. Melanoma-intrinsic beta-catenin signalling prevents anti-tumour immunity. Nature . 2015;523:231-235.

99. Ferrucci PF, Ascierto PA, Pigozzo J, et al. Baseline neutrophils and derived neutrophil-to-lymphocyte ratio: prognostic relevance in metastatic melanoma patients receiving ipilimumab. Ann Oncol. 2016;27:732-738.

100. Lin G, Liu Y, Li S, et al. Elevated neutrophil-to-lymphocyte ratio is an independent poor prognostic factor in patients with intrahepatic cholangiocarcinoma. Oncotarget. 2016;7:50963-50971.

101. Martens A, Wistuba-Hamprecht K, Geukes Foppen M, et al. Baseline peripheral blood biomarkers associated with clinical outcome of advanced melanoma patients treated with ipilimumab. Clin Cancer Res. 2016;22:2908-2918.

102. Weide B, Martens A, Hassel JC, et al. Baseline biomarkers for outcome of melanoma patients treated with pembrolizumab. Clin Cancer Res. 2016;22: 5487-5496.
103. Zaragoza J, Caille A, Beneton N, et al. High neutrophil to lymphocyte ratio measured before starting ipilimumab treatment is associated with reduced overall survival in patients with melanoma. $\mathrm{Br} J$ Dermatol. 2016;174:146-151.

104. Jeyakumar G, Kim S, Bumma N, et al. Neutrophil lymphocyte ratio and duration of prior anti-angiogenic therapy as biomarkers in metastatic RCC receiving immune checkpoint inhibitor therapy. J Immunother Cancer. 2017;5:82.

105. Lalani AA, Xie W, Martini DJ, et al. Change in neutrophil-to-lymphocyte ratio (NLR) in response to immune checkpoint blockade for metastatic renal cell carcinoma. J Immunother Cancer. 2018;6:5.

106. Rosner S, Kwong E, Shoushtari AN, et al. Peripheral blood clinical laboratory variables associated with outcomes following combination nivolumab and ipilimumab immunotherapy in melanoma. Cancer Med. 2018;7:690-697.

107. Sun R, Champiat S, Dercle L, et al. Baseline lymphopenia should not be used as exclusion criteria in early clinical trials investigating immune checkpoint blockers (PD-1/PD-L1 inhibitors). Eur J Cancer. 2017;84:202-211.

108. Subrahmanyam PB, Dong Z, Gusenleitner D, et al. Distinct predictive biomarker candidates for response to anti-CTLA-4 and anti-PD-1 immunotherapy in melanoma patients. J Immunother Cancer. 2018;6:18.

109. Krieg C, Nowicka M, Guglietta S, et al. High-dimensional single-cell analysis predicts response to anti-PD-1 immunotherapy. Nat Med. 2018;24:144-153.

110. Meyer C, Cagnon L, Costa-Nunes CM, et al. Frequencies of circulating MDSC correlate with clinical outcome of melanoma patients treated with ipilimumab. Cancer Immunol Immunother. 2014;63:247-257.

111. Cha E, Klinger M, Hou Y, et al. Improved survival with T cell clonotype stability after anti-CTLA-4 treatment in cancer patients. Sci Transl Med. 2014;6:238ra270.

112. McNeel DG. TCR diversity - a universal cancer immunotherapy biomarker?. J Immunother Cancer. 2016;4:69.

113. Robert L, Tsoi J, Wang X, et al. CTLA4 blockade broadens the peripheral T-cell receptor repertoire. Clin Cancer Res. 2014;20:2424-2432.

114. Huang AC, Postow MA, Orlowski RJ, et al. T-cell invigoration to tumour burden ratio associated with anti-PD-1 response. Nature. 2017;545:60-65.

115. Queirolo P, Morabito A, Laurent S, et al. Association of CTLA-4 polymorphisms with improved overall survival in melanoma patients treated with CTLA-4 blockade: a pilot study. Cancer Invest. 2013;31:336-345.

116. Breunis WB, Tarazona-Santos E, Chen R, Kiley M, Rosenberg SA, Chanock SJ. Influence of cytotoxic T lymphocyte-associated antigen 4 (CTLA4) common polymorphisms on outcome in treatment of melanoma patients with CTLA-4 blockade. J Immunother. 2008;31: 586-590.

117. Vetizou M, Pitt JM, Daillere R, et al. Anticancer immunotherapy by CTLA-4 blockade relies on the gut microbiota. Science. 2015;350:1079-1084.

118. Sivan A, Corrales L, Hubert N, et al. Commensal Bifidobacterium promotes antitumor immunity and facilitates anti-PD-L1 efficacy. Science. 2015:350:1084-1089.

119. Routy B, Le Chatelier E, Derosa L, et al. Gut microbiome influences efficacy of PD-1-based immunotherapy against epithelial tumors. Science. 2018;359:91-97.

120. Matson V, Fessler J, Bao R, et al. The commensal microbiome is associated with anti-PD-1 efficacy in metastatic melanoma patients. Science. 2018;359:104-108.

121. Chaput N, Lepage P, Coutzac C, et al. Carbonnel, baseline gut microbiota predicts clinical response and colitis in metastatic melanoma patients treated with ipilimumab. Ann Oncol. 2017;28:1368-1379.

122. Blank CU, Haanen JB, Ribas A, Schumacher TN. CANCER IMMUNOLOGY. The “cancer immunogram”. Science. 2016;352:658-660 


\section{Publish your work in this journal}

Cancer Management and Research is an international, peer-reviewed open access journal focusing on cancer research and the optimal use of preventative and integrated treatment interventions to achieve improved outcomes, enhanced survival and quality of life for the cancer patient. The manuscript management system is completely online and includes a very quick and fair peer-review system, which is all easy to use. Visit http://www.dovepress.com/testimonials.php to read real quotes from published authors.

Submit your manuscript here: https://www.dovepress.com/cancer-management-and-research-journal 